\title{
ESCOLA SEM PARTIDO E SEM GÊNERO: REDEFINIÇÃO DAS FRONTEIRAS PÚBLICO E PRIVADO NA EDUCAÇÃO
}

\author{
Carlos Eduardo Barzotto (UFRGS)* \\ https://orcid.org/0000-0003-3355-0087 \\ Fernando Seffner(FACED/UFRGS)** \\ https://orcid.org/0000-0002-4580-6652
}

\section{RESUMO}

Este artigo é um desdobramento de uma agenda de pesquisa que investiga algumas das relações entre educação e gênero. Nele, objetiva-se discutir teoricamente a influência de discursos neoliberais e (neo)conservadores nas políticas educacionais tomando como partida o sintagma "ideologia de gênero" e o Movimento Escola sem Partido. A partir dos estudos foucaultianos sobre neoliberalismo e de estudos sobre a nova onda conservadora mundial, defendemos que o sintagma "Ideologia de Gênero", bem como "Escola Sem Partido", são utilizados como estratégias discursivas de modo a unificar demandas neoliberais e (neo)conservadoras. A partir dessa união, é diminuído o caráter republicano da educação brasileira, substituindo-o pelo caráter moral e e pela racionalidade neoliberal focada no modelo empresarial.

Palavras-chave: Ideologia de gênero. Escola sem Partido. Educação. Neoliberalismo. Neoconservadorismo.

\section{ABSTRACT \\ SCHOOL WITHOUT PARTY AND GENDER: REDEFINING PUBLIC AND PRIVATE BORDERS IN EDUCATION}

This paper draws from an agenda of research that inquires about some of the relations between education and gender. Here we discuss in a theoretical way the influence of neoliberal and (neo)conservative discourses in education public policies starting with the expression "Gender Ideology" and the Movement Escola sem Partido. From foucauldian studies on neoliberalism and from studies on the new conservative global wave, we argue that the expression "Gender Ideology", as well as "Escola Sem Partido", are used as discursive strategies in order to unify neoliberal and (neo)conservative requests. From this union, the republican character of Brazilian education is diminished, being replaced by the

* Licenciado em História pela Universidade Federal do Rio Grande do Sul (UFRGS). Professor de História na Prefeitura Municipal de Guaíba. E-mail: cebarzotto@gmail.com

** Doutor em Educação pela Universidade Federal do Rio Grande do Sul (UFRGS). Professor da Faculdade de Educação da Universidade Federal do Rio Grande do Sul (FACED/UFRGS). E-mail: fernandoseffner@gmail.com 
moral character and by the neoliberal rationality focused on the business model. Keywords: Gender ideology. Escola sem Partido. Education. Neoliberalism. Neoconservatism.

\section{RESUMEN \\ ESCUELA SIN PARTIDO POLÍTICO Y SIN GÉNERO: REDEFINIENDO LAS FRONTERAS PÚBLICAS Y PRIVADAS EN LA EDUCACIÓN}

Este artículo es un desarrollo de una agenda de investigación que analiza algunas de las relaciones entre la educación escolar y las cuestiones de género. Discutimos aquí teóricamente la influencia de los discursos neoliberales y neoconservadores en las políticas educativas, tomando como punto de partida la consigna "ideología de género" y el movimiento "Escuela sin partido político". Con base en los estudios de Michel Foucault sobre el neoliberalismo y los estudios sobre la nueva ola conservadora global, defendemos que la consigna "Ideología de género" o "Con mis hijos no te metas", así como "Escuela sin partido político", se utilizan como estrategias discursivas para unificar las demandas neoliberales y neoconservadoras. Uno de los efectos de esta unión discursiva es disminuir el carácter republicano de la educación brasileña, reemplazándola por el carácter moral y la racionalidad neoliberal centrada en el modelo de negocios.

Palabras clave: Ideología de género. Escuela sin partido político. Educación. Neoliberalismo. Neoconservadurismo.

\section{Entre cenas e proposições}

No início de 2019, Damares Alves, recém -empossada ministra da Mulher, Família e Direitos Humanos pelo governo Jair Bolsonaro, aparece em vídeo dizendo estar inaugurando uma nova era, na qual "menino veste azul e menina veste rosa” (PAINS, 2019). Na mesma semana, a ministra também se manifestou dizendo que, durante sua atuação no governo, "menina será princesa e menino, príncipe" (ALENCASTRO, 2019). Nessas situações, ela alerta contra o que chama de doutrinação ideológica, que seria feita nas escolas públicas brasileiras, nas quais as crianças teriam sua sexualidade e/ou sua identidade de gênero confundidas e induzidas pelos professores e pelas professoras.

No final no mesmo ano, o presidente Jair Bolsonaro também citou a questão em seu Twitter, dizendo que proporia ao Ministério da Educação (MEC) a construção de um projeto de lei que proibisse o ensino do que ele chama de "ideologia de gênero" nas escolas brasileiras (CANCIAN; SALDAÑA, 2019). Dentre as justificativas dadas pelo governo em relação ao assunto, consta a suposta necessidade de construir um ensino neutro, aliado também à luta por uma Escola sem Partido. Tanto a fala da ministra quanto a do presidente manifestam um desejo pela volta de certas normas e princípios morais relacionadas ao gênero e à sexualidade dos indivíduos, potencializadas por sua forte atuação junto às bases religiosas (neo)pentecostais. Em suas retóricas, o Estado teria a função de (re)moralizar tais questões junto à arena pública. De modo conexo, os mandatários do Governo Federal indicam a necessidade de eliminar temas considerados "ideológicos" das grades curriculares.

Tais ações do governo podem ser vistas como paradoxais ou até mesmo sem conexão entre si. Por isso, o propósito deste artigo vai na mão contrária às ideias do governo; buscamos 
estabelecer conexões entre dois movimentos sociais de matriz conservadora muito atuantes nos últimos anos no país, intitulados aqui doravante como escola sem partido e ideologia de gênero. 0 ponto de encontro desses dois movimentos dá-se em um conjunto de estratégias discursivas que incidem na (re)definição das fronteiras entre o público e o privado no contexto da neoliberalização da educação pública. É nesse contexto que as falas acima citadas criam sentido estratégico definido e que os dois movimentos atuam em sinergia, mesmo quando os participantes de cada um não estão operando em conjunto. Portanto, assumimos neste texto que há mais elementos em comum entre os dois movimentos do que aparentemente se possa visualizar. De início, reforçamos o que já se anuncia no título: os dois movimentos desejam a educação escolar "sem" alguma coisa: gênero ou partido. Se a escola, e dentro dela professores e professoras, não pode abordar temas de gênero e temas políticos, tidos como "ideológicos", a questão que podemos levantar é: cabe a quem então educar crianças e jovens nesses assuntos?

De modo inicial, já damos uma pista de resposta: tais temas são "de responsabilidade" da família e da religião, não cabendo à escola neles se intrometer, sob pena de "afrontar" os valores familiares e religiosos, provocando "confusão" na formação das crianças. Os termos que acima utilizamos entre aspas aparecem com frequência nas argumentações dos projetos de lei encaminhados pelos dois movimentos, tanto no âmbito estadual como no federal. As manifestações e estratégias utilizadas por essas mobilizações deixam à mostra certa percepção de que a escola pública brasileira, nos últimos anos, veio progressivamente instaurando programas de ensino em temas de gênero, sexualidade, questões políticas em geral e valores culturais, e isso desagradou setores da sociedade. Com isso, a escola teria "exacerbado" suas funções, invadindo terrenos próprios da família e da religião. Logo, criminalizar professores e professoras, vistos como "estupradores intelectuais" dos jovens, foi um passo. A expressão "estupro intelectual", sob todos os aspectos bastante violenta, consta em numerosas manifestações, verbais e escritas, do fundador do Escola sem Partido, Miguel Nagib, conforme discutido por Penna e Salles (2017).

Há outro motivo que pode levar a pensar tais ações do governo como paradoxais, se tomarmos em conta sua agenda econômica. Marcado pelo neoliberalismo, o governo Bolsonaro avança no desmantelamento de políticas sociais (cortando verba de pastas como a Educação e a Saúde) e enxugando leis previdenciárias e trabalhistas, no rumo do que em geral se denomina como "flexibilização". Como estratégia neoliberal, visa diminuir a atuação do Estado em diversas esferas, abrindo espaço para a atuação pelo direito privado (DARDOT; LAVAL, 2016). Ainda assim, como tal racionalidade neoliberal convive simultaneamente com a exigência de maior controle estatal no âmbito moral advinda de uma racionalidade conservadora? Dito de outra forma, como as exigências neoliberais convivem com as exigências conservadoras, uma vez que elas seriam aparentemente contraditórias em uma série de questões? Afinal, se as políticas econômicas advogam em favor de um Estado minimamente regulador e miram a produção de um sujeito empreendedor liberal individualista, não haveria contradição em estabelecer censuras morais a comportamentos, conteúdos e modos de existir que sequer estão tipificados como crimes?

Esse paradoxo foi identificado por Wendy Brown (2019), ao analisar a eleição do presidente Donald Trump; ela propõe que, sobretudo após a crise de 2008, foi necessária uma união entre neoliberalismo e neoconservadorismo, de modo a assegurar o avanço de suas agendas no meio público. Trata-se, para essa autora, de uma forma de ocupar a arena pública com demandas do direito privado, em um processo por ela denominado de desdemocratização, que buscaria formar sujeitos 
baseados no empreendedorismo liberal e na atuação cristã (BROWN, 2015).

Já no dia da posse, em 1ํo de janeiro de 2019, Jair Bolsonaro fez duas falas oficiais, nas quais se mesclavam questões da ordem do empreendedorismo liberal e da moral cristã, conforme analisado por Corrêa e Kalil (2020, p. 22):

En el Congreso afirmó que su proyecto se resumiría en 'unir a la gente, valorar a la familia, respetar las religiones y nuestra tradición judeocristiana, luchar contra la ideología de género, preservar nuestros valores. Brasil volverá a ser un país libre de lazos ideológicos'. Además del énfasis puesto en el tema 'ideología y género', su discurso en el Congreso incluyó un agradecimiento a Dios por haber sobrevivido al ataque en el que fue apuñalado durante la campaña electoral y mencionó la creación de empleos, la importancia de la agroindustria, la liberación de armas para que la población 'ejerciera su derecho a la legítima defensa' y ofreciera 'apoyo legal a los agentes de policía para que lleven a cabo su trabajo'. En un tono menos formal y más objectivo, con motivo de la recepción de la banda presidencial, definió el día de su toma de posesión como 'el día en que el pueblo comenzó a liberarse del socialismo, a liberarse de la inversión de valores, del gigantismo estatal y de la corrección política'.

A partir dessa proposição - união entre neoliberalismo e neoconservadorismo -, este artigo tem como objetivo principal sugerir que o sintagma "ideologia de gênero" pode ser entendido, no caso brasileiro, como uma das estratégias discursivas que unem a racionalidade neoliberal a um tipo específico de racionalidade conservadora. Buscamos, então, fazer considerações sobre a relação entre o sintagma "ideologia de gênero" e o processo de neoliberalização da educação, visto que "ainda é preciso analisar de perto [...] objetivos e os métodos" (DARDOT; LAVAL, 2016, p. 272) empregados pelas estratégias neoliberais. Ressaltamos, ainda, a utilização de estratégias similares entre os movimentos antigênero e o movimento Escola sem Partido, uma vez que eles apoiam um ao outro e fortalecem-se quando unidos (PENNA, 2017), da mesma forma que apresentam objetivos similares: trata-se, em ambos os casos, de privatizar o espaço público da escola, o que não necessariamente significa eliminar a gratuidade da escola pública brasileira, mas implica modos de gestão e desenhos curriculares que deixam de lado valores públicos em benefício de valores da ordem do mercado e do privado.

Considerando que tais estratégias vêm (re) definindo as fronteiras entre o espaço público e o privado nos contextos educacionais em escala global e nacional (PERONI; CAETANO; ARRELARO, 2019), cremos que tais análises são essenciais para compreender os efeitos da invasão do âmbito privado no âmbito público e democrático. 0 que aqui entendemos por privado diz respeito a instituições diversas, mas em particular duas delas, a família e a religião, tomadas assim mesmo, no singular, pois ao dizer família normalmente esse discurso trata da família cristã, monogâmica, heterossexual, branca, urbana, de classe média e preservando a tradicional hierarquia marido, mulher e filhos, na ordem do maior poder para o menor poder. E por religião, certamente, o suposto é sempre um conjunto de religiões do tronco judaico cristão, com forte ênfase no que se convencionou chamar de religiões neopentecostais.

De modo a desenvolvermos nosso argumento, procederemos de uma discussão teórica centrada no movimento ideologia de gênero e estabelecendo conexões com o movimento Escola sem Partido. Para tanto, será apresentada, em um primeiro momento, a emergência do sintagma "ideologia de gênero" e algumas de suas principais estratégias. Em seguida, discutiremos sua relação com a construção da racionalidade neoliberal como forma de povoar o ambiente público e republicano com demandas empreendedoras. Finalmente, proporemos que tal povoamento não é apenas necessário para o desenvolvimento da racionalidade neoliberal, mas também como forma de (re)cristianizar o espaço público que estava sendo laicizado. É na relação entre esses dois povoamentos que está, então, o uso do sintagma "ideologia 
de gênero". E é também nessa relação que a parceria e complementaridade de ações entre os movimentos Escola sem Partido e ideologia de gênero expressa-se.

\section{"Ideologia de Gênero": afinal, o que é isso?}

De 2011 para cá, o Brasil vem sendo palco de intensos debates relacionados à inserção dos conceitos de gênero e sexualidade em políticas públicas, sobretudo em políticas públicas educacionais. Desde a polêmica envolvendo a aprovação e posterior veto do kit anti-homofobia (conhecido como "kit gay") em 2011, que até hoje repercute, conforme discutido por Ferreira e Leão (2019), até a tentativa de censura do presidente da república ao cinema nacional LGBT+ em 2019 (URIBE, 2019), muitos debates sobre o assunto foram e serão travados. Uma das questões centrais sobre esse assunto é: deve ou não a chamada "ideologia de gênero" avançar em nossas políticas públicas? Nesse sentido, cremos ser necessário esclarecer que "ideologia de gênero" não é sinônimo de estudos de gênero. Os estudos de gênero representam um conjunto de teorizações e pesquisas em âmbito acadêmico que surgiram relacionadas a questionamentos sobre a saturação dos chamados Estudos da Mulher (LOURO, 1997). 0 conceito "gênero" tinha, nesse momento, o objetivo de "enfatizar o caráter fundamentalmente social das distinções baseadas no sexo", negando o uso do "determinismo biológico implícito no uso de termos como 'sexo' ou 'diferença sexual'" (SCOTT, 1995, p. 72, grifo do autor).

Com isso em mente, as teorizações feministas passaram a questionar as definições sexuais do que era considerado masculino e feminino. A partir desses questionamentos, muitos movimentos foram feitos em escala global para denunciar e agir contra desigualdades de gênero, como a IV Conferência Mundial sobre as Mulheres da ONU, em Beijing, em 1995 (ORGANIZAÇÃO DAS NAÇÕES UNIDAS, 2020). 0 Brasil, signatário da Plataforma de Ação advinda dessa conferência em específico, passou a criar secretarias específicas para o enfrentamento dessas desigualdades no governo do Presidente Luís Inácio Lula da Silva, que culminaram com a criação, por exemplo, dos Planos de Políticas para as Mulheres em 2004, 2008 e $2013 .{ }^{1}$

Da mesma forma, os estudos gays, lésbicos e queer passaram a defender que "[...] os significados que damos à sexualidade e ao corpo são socialmente organizados, sendo sustentados por uma variedade de linguagens que buscam nos dizer o que o sexo é, o que ele deve ser e o que ele pode ser" (WEEKS, 2010, p. 43).

Uma vez, então, que o movimento feminista desnaturalizava posições de sujeitos atribuídas a mulheres e homens, tais estudos enfocavam na questão social relacionada à sexualidade. Judith Butler (2017) foi além nesse ponto, ao afirmar que construímos nossas posições de sujeito a partir de uma matriz heterossexual, que compulsoriamente busca formar sujeitos que alinhem seu sexo biológico à identidade de gênero e orientação sexual tipicamente atribuídas a ele. A partir dessa formulação acadêmica e também pela ação de movimentos sociais, políticas públicas destinadas ao público LGBTQIA+ também foram construídas no Brasil. Exemplos disso são o Programa Brasil Sem Homofobia (BRASIL, 2004) e as seções destinadas às mulheres lésbicas nos Planos de Políticas Públicas para as Mulheres de 2008 e 2013.

Houve, porém, uma reação a esses avanços na inserção de temáticas de gênero e sexualidade na arena pública. Como mostra Mary Case (2016), essas reações são gestadas nas décadas de 1980 e 1990 e são marcadas por fortes reformulações na doutrina católica, que visam frear a laicização ocorrida em escala global. Para tanto, conforme argumenta Ro-

1 Cabe citar que esse avanço não se estende necessariamente a todas as mulheres. Como critica Judith Butler (2017), a categoria "mulher" é por vezes limitadora na ação feminista por conta de suas marcas raciais, sexuais etc. Desse modo, ao incluir políticas para "as mulheres", nem todas as feminilidades foram atendidas. Percebe-se, em algumas dessas políticas públicas, uma reiteração da figura da mulher cis-heterossexual e branca, por exemplo. 
gério Junqueira (2016), uma das estratégias utilizadas pela Igreja Católica foi a criação do sintagma "ideologia de gênero" para combater os avanços que citamos anteriormente, ao mesmo tempo em que a instituição religiosa renovava seu discurso em busca de novos fiéis. "Ideologia de gênero" é, portanto,

[...] um poderoso slogan, incendiando a arena política de dezenas de países, ao catalisar manifestações virulentas contra políticas sociais, reformas jurídicas e ações pedagógicas voltadas a promover os direitos sexuais e punir suas violações, enfrentar preconceitos, prevenir violências e combater discriminações (hetero) sexistas. (JUNQUEIRA, 2016, p. 230).

Os Estudos de Gênero são, portanto, um campo de estudos, ao passo que "ideologia de gênero" é um slogan criado para combater avanços da laicidade e da secularização em escala global. Por seu caráter polivalente, "ideologia de gênero" não é mais um monopólio da Igreja Católica, sendo agora utilizado por diversos atores sociais, como igrejas (neo) pentecostais e políticos, para ganhar um maior número de seguidores. Os movimentos antigênero - que utilizam tal sintagma - podem ser considerados transnacionais pelas articulações que demonstram (CORRÊA; KALIL, 2020), e atuam fortemente no que diz respeito ao combate a reformas educacionais que visam incluir a diversidade em currículos e práticas escolares, como ocorreu nos debates acerca do Plano Nacional da Educação de 2014 (MORENO, 2016). Tais movimentos antigênero estão intimamente relacionados, no Brasil, ao Programa Escola Sem Partido (PENNA, 2017) e com a atuação de uma série de políticos e partidos da ala (ultra)conservadora.

De modo a avançar na arena pública, os movimentos antigênero relacionam o sintagma "ideologia de gênero" a pânicos morais, em estratégia que também lembra a ação dos adeptos do Movimento Escola sem Partido. Aqui, variam apenas os elementos que podem promover tal pânico: de um lado o gênero, de outro as "ideologias" presentes nas falas de professoras e professores e que configuram o perigo de criar simpatia a certos partidos. Com eles, o combate ao ensino de questões relacionadas ao gênero e à sexualidade ganha mais repercussão e, então, esse discurso cria capilaridade. Assim como Rafaela Borges e Zulmira Borges (2018, p. 14), valendo-se de Cohen, vemos esse pânico como:

[...] um conjunto de eventos que emergem em determinados momentos e são tomados como uma ameaça aos valores e interesses sociais; eles são apresentados de maneira estereotipada pelos mass media e barreiras morais se fortalecem contra o surgimento desta situação vista como ameaçadora. Nesse sentido, especialistas com algum respaldo social, como líderes políticos e religiosos, dentre outros, vêm a público manifestar seus diagnósticos e resoluções. Logo, estratégias de enfrentamento são criadas ou recorre-se às já existentes, até que a polêmica se esvazie e desapareça.

Esses pânicos morais no caso das reações antigênero instigam, para recorrer às polêmicas e esvaziamentos de certos discursos,

[...] ansiedades coletivas e discursos de ódio, contra gays, lésbicas e pessoas trans em geral, e especificamente contra a atuação da "esquerda LGBT" na política nacional, que é construída como 'minoria barulhenta', desviante e ameaçadora, privilegiada, antidemocrática e autoritária, cuja vontade é imposta a uma maioria nacionalista cristã. [...] Produz-se desse modo um marco polarizado, que obriga governos (bem como parlamentares e membros do judiciário) e outros atores políticos a se pronunciarem de um lado ou outro da disputa, com grande custo se escolherem o polo não conservador. (CARVALHO; SÍVORI, 2017, p. 34, grifo do autor).

Para compreender o uso de "ideologia de gênero" a partir de pânicos morais, acreditamos ser necessário também compreender duas estratégias discursivas aliadas à utilização desse sintagma: a do aglutinante simbólico (PETÕ, 2015) e a do significante vazio (LACLAU, 2013). A primeira noção importante para essa construção, a de "significante vazio", é discutida, dentre outros, por Roman Kuhar e Aleš Zobec (2017), a partir das teorizações de Ernesto La- 
clau (2013). Ao analisar casos europeus, esses autores expõem que "gênero" se torna inimigo pluridimensional, "que pode ser moldado de diferentes formas para encaixar-se no objetivo concreto de um protesto político" (KUHAR, ZOBEC, 2017, p. 31). Desse modo, aproximar esse conceito desenvolvido no meio acadêmico pelos estudos feministas às demandas políticas (ultra)conservadoras implica esvaziar seu caráter científico de modo a torná-lo algo que não significa, em si, nada e, portanto, passível de tornar-se qualquer significado, ao sabor da conveniência do ataque político que se deseja desferir a este ou aquele adversário.

A partir disso, constrói-se uma nova narrativa a partir do uso do aglutinante simbólico. Com isso, colam-se ou aglutinam-se ao conceito de "gênero" outras expressões ou gatilhos que auxiliarão na criação de um pânico moral. "Ideologia de gênero" é, então, "[...] un término sombrilla que crea un sentido común capaz de alcanzar una gran audiencia" (AMAYA, 2017, p. 160-161). 0 perigo que a suposta ideologia proposta pelo sintagma poderia trazer à sociedade é, portanto, adaptada para o país ou a região com outros enunciados que provocam desconfortos ou ações da sociedade civil: é o caso da junção dela com "comunismo" na Rússia (MOSS, 2017), com "pedofilia" na Polônia (GRZEBALSKA, 2015), com dominação colonial na Hungria (FÉLIX, 2015), com "Islã" na Áustria (MAYER; SAUER, 2017) e com as FARCs na Colômbia (MUELLE, 2017). No caso brasileiro, poderíamos citar a fake news produzida em 2018, que afirmava que o então candidato à presidência, Fernando Haddad (PT), era o responsável pela distribuição de mamadeiras com bicos em formatos fálicos em creches (MAMADEIRAS..., 2018), e que tudo isso tinha como objetivo "destruir a família".

Feita a separação entre "ideologia de gênero" e estudos de gênero, e elencadas algumas de suas principais estratégias, procedemos a realizar o debate proposto neste artigo. Questionamos, nesse sentido: como o movimento antigênero e o (ultra)conservadorismo se re- lacionam? Como essa relação se produz em um contexto de neoliberalização da educação? Que conexões se estabelecem entre essas diretrizes e as ações do Escola sem Partido?

\section{Neoliberalismo e o assalto do caráter republicano da escola pública}

A discussão sobre a definição de neoliberalismo é longa demais para o escopo deste trabalho, pois trata-se de um conceito polissêmico, e muito controverso, além de já apresentar longa trajetória histórica. De modo geral, podemos dizer que nos alinhamos às teorizações feitas por e a partir da obra O Nascimento da Biopolítica (FOUCAULT, 2008), que reúne os cursos ministrados por Michel Foucault no Collège de France entre 1978 e 1979. De acordo com o que é proposto por esse autor, o neoliberalismo não deve ser entendido apenas como uma ideologia ou como uma estratégia econômica de diminuição do Estado, como frequentemente é feito pela perspectiva marxista. Pierre Dardote Christian Laval (2016, p. 24) corroboram essa crítica ao criticar tal perspectiva, visto que:

Além de fazer da economia a única dimensão do neoliberalismo, [a leitura marxista] pressupõe que a burguesia é um sujeito histórico que perdura no tempo, que preexiste às relações de luta que engaja com as outras classes e que somente precisou alertar, influenciar e corromper os políticos para que estes abandonassem políticas keynesianas e as fórmulas de compromisso entre o trabalho e o capital. [...] Na realidade, não houve um grande complô nem uma doutrina pré-fabricada que os políticos teriam aplicado com cinismo e determinação para satisfazer as expectativas de seus poderosos amigos do mundo dos negócios. A lógica normativa que acabou se impondo constituiu-se ao longo de batalhas inicialmente incertas e de políticas frequentemente tateantes. A sociedade neoliberal em que vivemos é fruto de um processo histórico que não foi integralmente programado por seus pioneiros; os elementos que a compõem reuniram-se pouco a pouco, interagindo uns com os outros, fortalecendo uns aos outros. 
De modo a analisar a questão de forma diversa, Foucault (2008) propõe que o neoliberalismo é, assim como o liberalismo, uma arte de governar, em que o Estado tem legitimidade para agir (ou deixar de agir) em determinadas áreas e situações. Apesar dessa semelhança, ver o neoliberalismo apenas como uma atualização do liberalismo seria errôneo. De acordo com o filósofo francês,

[...] o neoliberalismo atual não é, de maneira nenhuma, como se diz muitas vezes, a ressurgência, a recorrência de velhas formas de economia liberal, formuladas nos séculos XVIII e XIX, que o capitalismo atualmente reativaria, por certo número de razões relacionadas tanto a sua impotência, as crises que ele atravessa, quanto a certo número de objetivos políticos ou mais ou menos locais e determinados. Na verdade, o que está em questão nesse neoliberalismo atual [...] é uma coisa muito mais importante. 0 que está em questão é saber se, efetivamente, uma economia de mercado pode servir de princípio, de forma e de modelo para um Estado [...]. (FOUCAULT, 2008, p. 159).

Se o neoliberalismo deve ser entendido como uma arte de governar, então ele caracteriza-se por uma série de estratégias e tecnologias que visam constituir sujeitos alinhados ao seu projeto de desenvolvimento. Assim, "o neoliberalismo é um sistema de normas que hoje estão profundamente inscritas nas práticas governamentais, nas políticas institucionais, nos estilos gerenciais" (DARDOT; LAVAL, 2016, p. 30). A partir disso, poderíamos questionar: Qual é, então, a ação do Estado em uma racionalidade neoliberal? E quais serão seus esforços para formar sujeitos alinhados a essa racionalidade? E como isso se reflete no campo educacional?

O liberalismo, no século XVIII, acreditava que o mercado era o regulador natural da sociedade. A partir de sua ação (troca, demanda, oferta), a sociedade seria regulada, contanto que a ação estatal não interferisse nesse funcionamento. Como argumentam Dardot e Laval (2016), porém, o neoliberalismo faz um movimento oposto: a partir da crise do liberalismo no final da década de 1920, o mercado passa a ser visto como desejável, mas não natural. 0 Estado passa a ser visto, nesse contexto, como agente legitimo para criar condições de possibilidade para as ações do mercado, não mais vistas como naturais. $\mathrm{O}$ aparelho estatal deve estimular, então, a concorrência na sociedade, de modo que ela sirva para o funcionamento mercantil. Desse modo,

[...] trata-se não de limitar o mercado por uma ação de correção ou compensação do Estado, mas de desenvolver e purificar o mercado concorrencial por um enquadramento jurídico cuidadosamente ajustado. Não se trata mais de postular um acordo espontâneo entre os interesses individuais, mas de produzir as condições ótimas para que o jogo de rivalidade satisfaça o interesse coletivo. A esse respeito, [...] o neoliberalismo combina a reabilitação da intervenção pública com uma concepção do mercado centrada na concorrência. (DARDOT; LAVAL, 2016, p. 69).

Quais seriam, então, as interferências estatais a serem realizadas nesse contexto? Como poderia o Estado maximizar os efeitos da concorrência, criando estratégias junto à sociedade para potencializar uma racionalidade neoliberal? Para Dardot e Laval (2016), a escola é um ponto central nesse cenário. Assim como ela produzia corpos alinhados às demandas da modernidade, em que indivíduos se subjetivavam a partir do poder disciplinar (FOUCAULT, 2014), agora a escola é vista como potencial formadora de uma nova forma de subjetivação, formando um sujeito -empreendedor, que é a empresa de si mesmo. Nesse contexto, Silva, Silva e Vasques (2018) argumentam que a escola brasileira, como pode ser visto a partir dos exemplos da constituição da Base Nacional Comum Curricular (BNCC) e da Reforma do Ensino Médio, passa por um processo de financeirização. Nesse sentido, a instituição é colocada a serviço do mercado - sobretudo financeiro - em que são estimuladas as propostas pedagógicas que fomentem o desenvolvimento do sujeito-empreendedor. Em outro trabalho, Vera Peroni, Maria Caetano e Lisete Arrelaro (2019, p. 38) 
chamam esse processo de mercantilização, que seria:

0 processo de mercantilização ocorre também com o privado definindo o conteúdo da educação. Observamos, em parte, o poder público assumindo a lógica do privado na administração pública, através da gestão gerencial e, também, quando abre mão de decidir o conteúdo da educação, repassando a direção para instituições privadas. Nesse caso, a propriedade permanece pública, mas a direção do conteúdo das políticas educativas é repassada para o setor privado. As instituições públicas, se democráticas, são permeáveis à correlação de forças, com processos decisórios em que não se tem previamente o controle do produto. São instituições de propriedade pública, mas se o processo decisório está ausente, já que tudo é previamente definido e monitorado por uma instituição privada e os professores apenas executam tarefas, entendemos que este também é um processo de privatização da educação.

A escola pública manteria, então, sua aparência republicana e democrática e até mesmo sua gratuidade, mas não suas atitudes, valores, conteúdos, modos de avaliação e estatuto dos saberes. Há, ainda, atores políticos que propõem o fim da escola pública e distribuição de vouchers educacionais no país, aprofundando o vínculo entre valores familiares e escolha do regime de escolarização. Em ambos os casos, a lógica da educação republicana se inverte. Diferente de uma educação focada na formação do pensamento crítico ou humanista, por exemplo, a educação neoliberal foca na "lógica adaptativa" (DARDOT; LAVAL, 2016, p. 92) do sujeito à flexibilidade do mercado e à gestão do risco.

Não por acaso, a Base Nacional Comum Curricular (BNCC) foi financiada por uma série de associações privadas, tais como Itaú, Gerdau, Instituto Lemann, Movimento Todos Pela Educação e Instituto Ayrton Senna (MACEDO, 2014). A BNCC, inclusive, propõe competências socioemocionais, de modo a preparar os sujeitos para as dificuldades de seus projetos de vida e de mercado de trabalho, no contexto da financeirização (SILVA; SILVA; VASQUES, 2018).
Da mesma forma, tal texto curricular corrobora uma estratégia já anunciada na Reforma do Ensino Médio: a culpabilização. Na educação neoliberal, é preciso "considerar o indivíduo plenamente responsável" (DARDOT; LAVAL, 2016, p. 213) por seu processo educacional, visto que ele poderá escolher seus itinerários formativos. Dessa forma, problemas decorrentes da suposta "escolha" serão creditados a cada aluno ou aluna, e não ao sistema. A noção de escolha, intensamente explorada no contexto da reforma do Ensino Médio pela propaganda junto aos jovens, em materiais audiovisuais dos quais alunos e alunas alegremente repetiam o mantra "agora vou poder escolher o que quero fazer", esconde o debate dos limites das reais possibilidades de escolha, sempre muito restritas e precárias quando se trata da escola ofertada para a maioria da população.

A educação das massas é, então, "crucial para el funcionamento del neoliberalismo" (VEIGA-NETO, 2010, p. 228), uma vez que é através dela que parte da racionalidade neoliberal é capilarizada. Trata-se, então, de fomentar uma educação empreendedora, em que o sujeito-empreendedor aprenda a portar-se no mercado de trabalho, bem como aprenda a desenvolver as características exigidas para ele, como a pró-atividade, a liderança, o empreendedorismo. Não por acaso, "o combate ideológico é parte integrante do bom funcionamento da máquina" (DARDOT; LAVAL, 2016, p. 150-151). Sendo a formação de um indivíduo marcada por uma escola supostamente não ideológica e por uma empresa, diminui-se o espaço para o pensamento crítico e, assim, abre-se espaço para a construção do sujeito-empreendedor. Utilizar os espaços, aparelhos e instituições públicas para o serviço da racionalidade neoliberal configura o que Dardot e Laval (2016) chamam de construir o ideal de uma sociedade de direito privado. Utiliza-se, assim, a lei - a partir da qual a jurisdição governamental é exercida - de modo a servir ao âmbito privado, bem como permitir a sua entrada no âmbito público. 
Esse processo, caracterizado por Wendy Brown (2015) como desdemocratização, implica não só no esvaziamento do meio público, como também naquilo que o sustenta e o legitima. Valendo-se da argumentação de Michel Foucault (2008), Brown (2015) propõe haver uma disputa entre o homo politicus e o homo oeconomicus nesse contexto. 0 primeiro, de acordo com essa autora, é caracterizado pelas construções liberais do século XVIII, em que o ser humano é dotado de uma série de direitos básicos, que ele é capaz de exercer na sociedade, sobretudo no espaço público, desde que sejam respeitadas as leis. Sua construção, assim, foca-se no humanismo iluminista, independentemente da situação econômica a qual ele está submetido. ${ }^{2}$ Já o segundo, fortalecido pela ascensão do neoliberalismo, tem o privado como lócus de atuação, e suas demandas individuais vistas como superiores às demandas públicas (BROWN, 2015).

Michel Foucault não viveu para fazer o que Brown (2015) denomina supressão do homo politucus pelo homo oeconomicus. Segundo essa autora, a partir do final do século XX, uma nova forma de racionalidade toma forma, a partir da soberania da demanda privada em relação à atuação pública. Não se trata, como já foi argumentado, de extinguir o âmbito público, e sim de esvaziá-lo de seu sentido público - e de sua característica democrática e republicana - de modo a o financeirizar. Vemos, assim, "toda a cidadania, tal como se construiu nos países ocidentais desde o século XVIII" (DARDOT; LAVAL, 2016, p. 380) sendo questionada. Desse modo,

Neoliberalismo é a racionalidade através da qual o capitalismo finalmente engole a huma-

2 Não foi esquecida, aqui, a crítica em relação à unidade do sujeito iluminista. Como argumenta Bonnie Smith (2003), o pensamento iluminista é marcado por sua construção masculina, uma vez que os filósofos da época não permitiam, no geral, a participação feminina no pensamento filosófico. Da mesma forma, o iluminismo apresenta limitações relacionadas às ideias de progresso, razão e raça. Reconhecendo essas críticas, insistimos também que, de acordo com Brown (2015), foi a partir daqui que o âmbito público passou a ser visto como local onde se exercem direitos humanos soberanos, como a liberdade e a igualdade. nidade - não apenas com sua maquinaria de comodificação compulsória e expansão guiada pelo lucro, mas sim por sua forma de avaliação. Enquanto a expansão dessa forma esvazia o conteúdo da democracia liberal e transforma todo o significado de democracia, ela subjuga desejos e ameaça sonhos democráticos. (BROWN, 2015, p. 44. tradução nossa). ${ }^{3}$

Eis aqui um ponto de conexão entre o avanço de movimentos antigênero no cenário educacional e o neoliberalismo: ambos visam destituir o espaço público de seu caráter republicano, em que a escola seria local de discussão e construção de pensamento crítico, e substitui -lo pelo caráter empreendedor. Com isso, seria refinada a construção do homo oeconomicus aliado à gestão do risco inerente à economia atual e à criatividade e o controle emocional requerido por empresas atualmente. 0 movimento Escola sem Partido atua com princípios e objetivos muito semelhantes, buscando em tudo eliminar o que lhe parece um conteúdo político, ideológico ou partidário nos aprendizados escolares, e faz isso alinhado à direção que acima mostramos. Clara está a impossibilidade de algo não ser simultaneamente técnico e político, narrativo e ideológico. Todavia, para esse movimento são determinadas opções políticas que devem ser excluídas da escola. De outras proposições políticas não se diz que sejam "ideológicas”. Exemplo emblemático desse comportamento foi a parceria estabelecida em 2017 entre a Secretaria de Educação do Município de São Paulo e o Instituto Mises Brasil para distribuição gratuita de livros nas escolas (CRÍTICO..., 2017). Os livros, produzidos pelo referido Instituto, tinham como objetivo ensinar aos alunos da rede municipal paulista noções básicas de economia, naquilo que se convencionou chamar de "educação financeira", e faziam isso promovendo os

3 "Neoliberalism is the rationality through which capitalism finally swallows humanity - not only with its machinery of compulsory commodification and profit-driven expansion, but by its form of valuation. As the spread of this form evacuates the content from liberal democracy and transforms the meaning of democracy tout court, it subdues democratic desires and imperils democratic dreams." 
princípios do livre mercado. A defesa desses princípios não foi considerada "ideológica", e o material não foi proibido de ser distribuído, sendo que o prefeito da época era um ferrenho defensor do Movimento Escola sem Partido. Ora, se discutimos, até então, a (re)definição da atuação do Estado de modo a proporcionar a construção de posições de sujeito alinhadas à racionalidade neoliberal, qual seria a relação dela com a "ideologia de gênero" e com certas formas de racionalidade conservadora?

\section{"Ideologia de gênero", neoliberalismo, conservadorismo e Escola sem Partido: pontos de encontro}

Em 2011, a Corte Europeia de Direitos Humanos julgou um pedido feito por membros da Igreja Batista. Tal processo, analisado por Ramin Kuhar e Aleš Zobec (2017), solicitava que os filhos daqueles que entraram com o pedido junto à Corte tivessem liberação de todo currículo escolar destinado à educação sexual. De acordo com os proponentes, as crianças haviam recebido orientação sobre o assunto em casa e, portanto, não precisariam estar expostas à "sexualização prematura" realizada nas aulas de educação sexual (KUHAR; ZOBEC, 2017). Além desse argumento, os proponentes diziam que discussões relacionadas a gênero na escola eram contrárias às suas escolhas religiosas e, a partir do direito de educar seus filhos e suas filhas de acordo com suas crenças, buscavam fortalecer sua causa. A Corte Europeia de Direitos Humanos negou o pedido, afirmando que "educação sexual obrigatória em escolas públicas não viola a liberdade parental de educar seus filhos de acordo com suas convicções religiosas e filosóficas" (KUHAR, ZOBEC, 2017, p. 42 , tradução nossa). ${ }^{4}$

4 "The Court ruled that compulsory sex education in public schools as such does not violate parental freedom to educate their children according to their religious and philosophical convictions."
A partir do que foi discutido anteriormente neste artigo, poderíamos separar tais argumentos relacionados à função atribuída à escola. De um lado, os pais (membros da Igreja Batista), que viam o seu direito individual de educar seus filhos e suas filhas como soberano em relação ao direito republicano que esses teriam de receber educação sexual. Por outro lado, a Corte Europeia de Direitos Humanos, com argumentos que reforçaram o direito daquelas crianças a receberam tal educação, sobretudo levando em conta sua presença em uma sociedade democrática e republicana. Ora, tal ação está geograficamente distante do caso brasileiro, mas as relações de poder ali envolvidas apresentam algumas similaridades. Afinal, o Supremo Tribunal Federal (STF) brasileiro julgou também, em 2018, uma ação relacionada ao homeschooling, e argumentos sobre o direito dos pais de educarem seus filhos foram utilizados aqui também (BRÍGIDO; MARIZ, 2018). Em ambos os casos, a questão religiosa e a liberdade aparecem como argumentos para destituir a ação pública.

Trouxemos esse caso europeu para ilustrar, inicialmente, a proximidade entre essa demanda e uma forma específica de conservadorismo. Conforme argumentamos anteriormente, as estratégias neoliberais visam ocupar a arena pública com o direito privado, de modo a formar um sujeito empreendedor. Gostaríamos de sugerir, em sequência, que o espaço dado à moral e à liberdade religiosa é, nesse contexto, essencial para possibilitar e potencializar o processo de desdemocratização que, na educação, passa pela restrição do ensino de determinadas questões, como as relacionadas ao gênero e à sexualidade, e muitas outras vistas como portadoras de conteúdos ditos ideológicos. A íntima relação estabelecida entre a racionalidade neoliberal e uma racionalidade conservadora é caracterizada por Wendy Brown (2019) como necessária para a manutenção da sociedade neoliberal. De acordo com essa autora, após a crise de 2008, as estratégias sociais, econômicas e políticas que 
vinham sendo empregadas entraram em crise e, de modo a manter sua posição, foi necessário que houvesse apoio mútuo entre retóricas neoliberais e conservadoras. É nesse ponto, para Brown (2019), que a campanha de Donald Trump ganha notoriedade: longe de preocuparse apenas com questões econômicas, a corrida presidencial pôde potencializar uma série de questões, como islamofobia, machismo, racismo e LGBTfobia, de modo a propulsionar uma nova agenda política capaz de superar a crise encontrada pelo neoliberalismo em 2008. Dito de outra forma: "A base evangélica de Trump não se importa com quem ele é ou com o que ele faz, contanto que ele cumpra suas promessas sobre Jerusalém, aborto, banimento de pessoas trans no exército, orações nas escolas, e direitos de empresas e indivíduos cristãos em discriminar" (BROWN, 2019, p. 172-173, tradução nossa). ${ }^{5}$

Causando pânicos morais sobre determinados assuntos, uma racionalidade conservadora cresce, aliada à expansão da racionalidade neoliberal. Cabe questionar, portanto, quais são os sujeitos constituintes desse conservadorismo, assim como quais são seus objetivos. Chamado por Brown (2006, p. 696, tradução nossa) ${ }^{6} \mathrm{de}$ "neoconservadorismo", ele seria composto de uma:

[...] convergência entre cristãos evangélicos, judeus straussianos, declarados seculares lutadores da Guerra Fria que criaram um fetiche sobre o Oeste, feministas conservadoras e outros moralistas da família (tipos como Lynne Cheney), imperialistas aleatórios, e liberais e socialistas convertidos.

Tais grupos teriam em comum, de acordo com essa autora, a utilização da religião "de modo a facilitar o apelo neoconservador na

5 “Trump's evangelical base does not care who he/is or what he does so long as he delivers on Jerusalem, abortion, the trans ban in the military, prayer in school, and the rights of Christian businesses and individuals to discriminate"

6 "Convergence of interests among evangelical Christians, Jewish Straussians, avowedly secular Cold Warriors who have made a fetish of the West, conservative feminists and other family moralists (Lynne Cheney types), random imperialists, and converted liberals and socialists." base popular, e especialmente de modo a construir a recepção por seu autoritarismo" (BROWN, 2006, p. 696, tradução nossa). ${ }^{7}$ Trata-se, assim, de uma composição autoritária, que vê a liberdade religiosa como sobreposta ao caráter democrático. É tal uso da liberdade religiosa, segundo essa autora, que liga a sua demanda à racionalidade neoliberal, uma vez que é a partir dela que se ataca a legitimidade do aparelho estatal centrado no homo politicus (BROWN, 2006). Já Rogério Junqueira (2018) chama os grupos que gestaram o sintagma "ideologia de gênero" de ultraconservadores. Segundo esse autor, tratar-se-ia de uma frente conservadora formada por:

Opus Dei, Comunhão e Liberação, Neocatecumenato, Renovação no Espírito Santo, Focolares, Legionários de Cristo, entre outros. Diferentes entre si e fiéis à tática do 'marchar divididos para bater juntos' a partir de 'princípios não negociáveis', esses movimentos engajam-se em uma Reconquista católica contra o relativismo e o secularismo em matérias de bioética, família, moral sexual e educação escolar (Zavattiero, 2013). A atuação dos quatro primeiros foi crucial na emergência, na disseminação do discurso antigênero e na organização de protestos contra a 'teoria/ ideologia do gender' (Paternotte, 2015a). Além deles, outras organizações religiosas ultratradicionalistas povoam a galáxia antigênero, como a Fraternidade Sacerdotal São Pio X (lefebvristas) e a Tradição, Família e Propriedade. (JUNQUEIRA, 2018, p. 451, grifo do autor).

Apesar da diferença de nomenclatura, ambas as posições caracterizam o atual ataque conservador como aliado a grupos religiosos que visam esvaziar o âmbito público - sobretudo no que diz respeito à laicização - de modo a (re)cristianizá-lo. Em resumo, as supostas liberdades individuais (religiosas) passam a ser vistas como superiores às liberdades instituídas pelo sistema republicano. Com isso, constituir-se-ia um direito privado na arena pública, que possibilitaria o desenvolvimento de

7 "In facilitating neoconservatism's appeal to a popular base, and especially in constructing a reception for its authoritarianism." 
um sujeito-empreendedor. Além disso, também cremos ser potente ecoar a argumentação de Brown (2019) no que diz respeito ao papel da moral religiosa nesse contexto: segundo essa autora, a racionalidade neoliberal busca nessa moral uma forma de criar posições de sujeito alinhados também a sua necessidade. Podemos supor que tal relação ocorre porque "a forma -empresa é a 'forma celular' de moralização do indivíduo trabalhador, do mesmo modo que a família é a 'forma celular' da moralização da criança". (DARDOT; LAVAL, 2016, p. 388, grifo do autor).

Desse modo, sendo a empresa a forma celular que forma o sujeito-empreendedor no contexto da neoliberalização e a família a forma celular que o moraliza, a constituição do sujeito-empreendedor está relacionada às duas formas celulares. Assim a moral familiar pregada pelos moralistas ultraconservadores estaria alinhada com a moral empreendedora pregada pela racionalidade neoliberal. Ora, não seriam esses os casos do julgamento da Corte Europeia de Direitos Humanos e do julgamento do homeschooling no Brasil? Trazemos, ainda, a argumentação de Luis Felipe Miguel (2016): o que é proposto pelo Programa Escola sem Partido - e, adicionamos nós, pelo movimento antigênero - é a primazia do direito dos pais sobre o direito dos alunos, visto que a liberdade de escolha dos pais é vista como superior à liberdade de aprender dos filhos, o que se explicita em um dos slogans utilizados pelos dois movimentos, que é "meus filhos, minhas regras". É, conforme argumentado, o esvaziamento do direito público em detrimento do direito privado, utilizando do sintagma "ideologia de gênero" como forma de argumentar a necessidade de "proteger as crianças" de um certo perigo, este bastante semelhante ao perigo que mobiliza os apoiadores do movimento Escola sem Partido.

No Plano Nacional de Educação (PNE), por exemplo, a expressão "gênero" foi retirada a partir de proposições tanto de parlamentares pertencentes às alas conservadoras (MORENO,
2016), quanto de parlamentares pertencentes às alas que poderiam ser caracterizadas por um projeto político neoliberal. Da mesma forma, os grupos neoliberais já citados que fizeram lobby na criação da Base Nacional Comum Curricular também se aliaram às demandas de líderes religiosos ao retirar o termo "gênero" e "identidade sexual" de uma série de componentes curriculares, como o de História (BARZOTTO, 2017). Um dos pontos de encontro entre a racionalidade neoliberal e a moral familiar conservadora é, portanto, o sintagma "ideologia de gênero". A partir dele, ataca-se a escola enquanto instituição de formação do caráter cidadão. Em primeiro lugar, segundo esses movimentos, educar para a concorrência e para o empreendedorismo. Em segundo lugar, porque ela é vista como um local perigoso em que as crianças podem ser doutrinadas a tornarem-se de esquerda ou a mudarem seus sexos - como alegam os defensores do movimento antigênero e do Escola sem Partido. Desse modo, o sintagma "ideologia de gênero" pode ser entendido como parte de um discurso da racionalidade neoliberal que visa (re)definir relações e fronteiras entre o público e o privado, esvaziando o primeiro em detrimento do crescimento do segundo.

\section{Juntando algumas pontas}

Reconhecemos a complexidade das questões envolvidas e nossa limitação de leituras e não nos atrevemos a tirar conclusões do que foi exposto. Preferimos a modalidade mais prudente de juntar algumas pontas, mostrar certas direções, insistir em determinadas conexões. Como pano de fundo importante, destacamos o conjunto de disputas que desde muito se estabelecem, em muitas sociedades, entre escolas, famílias e religiões pela gestão dos infantis e dos jovens. Não é de hoje que a negociação de fronteiras é tensa entre o que é "próprio" da família em termos de educação de seus filhos e suas filhas; o que é "próprio" da escola pública em termos de educação de seus alunos e suas 
alunas; e o que é "próprio" das religiões em termos de educação de seus fiéis. A disputa pela educação dos indivíduos na sociedade foi sempre acirrada, ainda mais quando esses são considerados ainda não plenamente capazes, e a balança pendeu para diferentes lados, em diferentes momentos históricos. A ampliação dos anos de escolaridade, em praticamente todos os países do mundo, e o avanço da escola de turno integral, ensejaram um conjunto um tanto contraditório de demandas. Por um lado, assistimos nas últimas décadas a uma proliferação de decretos, em especial nos âmbitos municipal e estadual, delegando à escola os aprendizados em questões como educação para o trânsito, educação para a paz, ensino religioso, educação das relações étnico-raciais, prevenção da violência, educação financeira, preparação para o trabalho, educação nutricional, formação cultural geral, entre outros aprendizados. 0 ensino religioso é objeto de legislação federal, embora tenha diferentes modos de cumprimento, a depender do que estados e municípios legislaram. Se compararmos documentos legais que estabelecem parâmetros educacionais dos últimos cinquenta anos no Brasil, veremos um avanço enorme na delegação de atribuições à escola. A isso se associa a demanda, presente em todas as classes sociais e regiões do país, pela escola de turno integral, aquela na qual as crianças ingressam logo cedo pela manhã e nela permanecem até o final da tarde, por vezes realizando ali até cinco refeições, e tendo acesso a aprendizados sobre muitos temas.

Ou seja, as mesmas famílias que discordam do aprendizado de um ou outro tema na escola, por vezes vivem em municípios onde as câmaras de vereadores obrigaram a escola a abordar estes temas. As mesmas famílias que afirmam que cabe a elas ensinar uma série de temas para seus filhos e filhas, são desejosas de matricular os filhos em escolas de turno integral, onde as crianças vão ter aulas de muitos dos temas que elas dizem ser de sua exclusividade ensinar. E as mesmas famílias que insistem na responsabilidade dos pais em educar seus filhos necessitam dispor de estabelecimentos de turno integral para lá colocar seus filhos e filhas desde os quatro anos, na educação infantil. Essas famílias têm direito a tais benefícios, e com isso os autores deste artigo concordam integralmente. Não há país do mundo que tenha tido sucesso na alfabetização de sua população e na correção das desigualdades que não disponha de um sólido sistema de educação pública, a começar pelos países que são elogiados pela atual presidência da República. De acordo com a legislação em vigor, crianças devem ir à escola a partir de quatro anos de idade, em escolas de educação infantil, nas quais terão à disposição professoras formadas nos cursos de Pedagogia, uma habilitação de ensino superior. A escolaridade é obrigatória por lei no país dos quatro aos dezoito anos, alcançando um total de quatorze anos, naquilo que adequadamente é chamado de educação básica. Educação básica, a saber, o conjunto básico de conhecimentos que devem ser adquiridos para viver em sociedade. Como o próprio termo indica, se é básico, não é aceitável menos do que isso. É forçoso reconhecer que tivemos, desde a promulgação da Constituição Federal de 1988, um enorme avanço na escolarização no país, com a inclusão de meninas, populações rurais, populações pobres, negros e negras, que estavam à margem do sistema. Embora com muitas precariedades, a escola tornou-se um importante elemento para a vida de crianças e jovens, e isso é algo a ser comemorado, e não combatido. Na mão contrária, o hábito de educar em casa, ou o hábito de acompanhar as aprendizagens dos filhos, decaiu. Se por um lado a presença evangélica é forte nos meios políticos hoje em dia, ela nem de longe é tão robusta quanto já foi o poder da Igreja Católica até a década de 1970 no país, a influenciar diretamente políticas públicas, eleições, regimes escolares, cerimônias cívicas, valores morais. 0 regime democrático instaurado a partir da Constituição Federal de 1988 no país efetuou importante redistribuição de poder entre numerosos atores sociais 
e tornou muito mais difícil o estabelecimento de consensos, o que é próprio da democracia. Sendo assim, vem a importância de uma vida política de qualidade, a negociar articulações entre pessoas e grupos sociais com posições diversas sobre praticamente todos os temas.

A esse cenário somaram-se, nas últimas duas décadas pelo menos, um avanço dos movimentos que aqui descrevemos, que são claramente reacionários, no sentido de pretender o reestabelecimento de hierarquias que vinham sendo questionadas. Essas hierarquias são aquelas que constituem objeto de polêmica e pânico moral hoje em dia: hierarquias de gênero, hierarquias de orientação sexual, hierarquias de cor da pele, hierarquias de classe, hierarquias entre moradores do campo e da cidade, hierarquias entre moradores das diferentes regiões brasileiras, hierarquias de geração entre jovens e adultos e pessoas velhas, hierarquias entre os deficientes e os que se pensam normais em termos de corpo, entre outras. É visível a ansiedade que provocam as tensões entre essas hierarquias nos regimes democráticos. Acreditamos que a democracia e o espaço público republicano são os mais adequados instrumentos para gerir tal diversidade. Contudo, assistimos, conforme demonstrado neste artigo, a um avanço que busca deslegitimar valores do espaço público. Para o caso do campo educacional, a afirmação "a educação é um direito" vem sendo objeto de sucessivos ataques, substituída por variadas formulações em que cada um é responsável por seu próprio percurso educacional e, portanto, culpado exclusivo do fracasso, se ele ocorrer. Em um país historicamente situado entre aqueles que apresentam os mais elevados índices de desigualdade dentre todas as nações do Globo, implementar, através de um discurso de meritocracia, a ideia de que cada um é inteiramente responsável pelos próprios caminhos de formação, como se todos tivessem, desde a partida, as mesmas condições, é algo que no mínimo promove considerável estrago quando pensamos em uma sociedade com justiça social. Não é demais lembrar que a Constituição Federal de 1988 abre afirmando que no Brasil existe um

Estado Democrático, destinado a assegurar o exercício dos direitos sociais e individuais, a liberdade, a segurança, o bem-estar, o desenvolvimento, a igualdade e a justiça como valores supremos de uma sociedade fraterna, pluralista e sem preconceitos, fundada na harmonia social e comprometida, na ordem interna e internacional, com a solução pacífica das controvérsias. (BRASIL, 1988).

A escola pública brasileira encontra-se no centro de um conjunto de polêmicas nos dias de hoje que mostram sua importância e ao mesmo tempo a faz vítima de muitos golpes. Professores e professoras, que são os profissionais que dão alma a esse espaço, estão hoje entre as categorias profissionais mais atacadas no país. Desenhar currículos, planejar aulas, orientar alunos e alunas, responder as demandas das comunidades escolares, obedecer ao que dizem as políticas públicas é, hoje em dia, tarefa que exige enorme esforço tanto de intelecto quanto de articulação. E estamos deixando de lado movimentos de negação das verdades científicas como o terraplanismo e questões como a da pós-verdade, mecanismo pelo qual alguns efetuam uma seleção afetiva, e não racional, das verdades nas quais vão acreditar. Educar crianças e jovens tornou-se, nos dias de hoje, empreendimento cercado de polêmicas e disputas, quando não de ameaças. 0 texto que ofertamos trouxe alguns elementos que, em nosso entender, ajudam a pensar certas direções que vêm sendo tomadas pelas políticas públicas e pelo debate político, a fim de auxiliar a desenhar respostas que aprofundem noções que acreditamos, como democracia e justiça social, e que possam dar corpo aos citados valores expressos na Constituição Federal de 1988.

\section{REFERÊNCIAS}

ALENCASTRO, Catarina. "Menina será princesa e menino, príncipe, diz a ministra da Mulher, Família e Direitos Humanos. 0 Globo, Rio de Janeiro, 02 de 
janeiro de 2019. Disponível em: https://oglobo. globo.com/sociedade/menina-sera-princesamenino-principe-diz-ministra-da-mulher-familiadireitos-humanos-23341446. Acesso em: 22 jan. 2020.

AMAYA, José F. S. La tormenta perfecta: ideologia de género y articulación de públicos. Sexualidad, Salud y Sociedad - Revista Latinoamericana, n. 27, p. 149-171, dic. 2017.

BARZOTTO, Carlos E. Constituindo um sujeito -histórico: identidades e narrativas (re)criadas nas três versões da Base Nacional Comum Curricular de História (2015, 2016, 2017). 2017. 55 f. Trabalho de Conclusão de Curso (Graduação em História) Departamento de História, Instituto de Filosofia e Ciências Humanas, Universidade Federal do Rio Grande do Sul (UFRGS), Porto Alegre, 2017.

BORGES, Rafaela O.; BORGES, Zulmira N. Pânico moral e ideologia de gênero articulados na supressão de diretrizes sobre questões de gênero e sexualidade nas escolas. Revista Brasileira de Educação [online], Rio de Janeiro, v. 23, jul. 2018. Disponível em: https://www.scielo.br/pdf/rbedu/ v23/1809-449X-rbedu-23-e230039.pdf. Acesso em: 22 jan. 2020.

BRASIL. Presidência da República. Casa Civil. Constituição da República Federativa do Brasil de 1988. Brasília, DF, 1988. Disponível em: http:// www.planalto.gov.br/ccivil_03/constituicao/ constitu)icaocompilado.htm. Acesso em: 05 jan. 2020.

BRASIL. Conselho Nacional de Combate à Discriminação. Brasil Sem Homofobia - Programa de Combate à Violência e à Discriminação contra GLTB e de Promoção da Cidadania Homossexual. Brasília, DF: Ministério da Saúde/Conselho Nacional de Combate à Discriminação, 2004. Disponível em: http://bvsms.saude.gov.br/bvs/ publicacoes/brasil_sem_homofobia.pdf. Acesso em: 10 jan. 2020.

BRÍGIDO, Carolina; MARIZ, Renata. STF decide que pais não podem educar filhos em casa, sem matricular em escola. 0 Globo, Rio de Janeiro, 12 de setembro de 2018. Disponível em: https://oglobo. globo.com/sociedade/stf-decide-que-pais-naopodem-educar-filhos-em-casa-sem-matricularem-escola-23062742?fbclid=IwAR3zeH4IUHP c8DnQAOFWHqYk3eIlIESYIpzsK9hSWy3ekKFx XzACEvQAzUA. Acesso em: 04 jan. 2020.

BROWN, Wendy. American nightmare: neoliberalism, neoconservatism, and de- democratization. Political Theory, v. 34, n. 6, p. 690-714, dez. 2006.

BROWN, Wendy. Undoing the demos: neoliberalism's stealth revolution. Zone Books: New York, 2015.

BROWN, Wendy. In the ruins of neoliberalism: the rise of antidemocratic politics in the West. New York: Columbia University Press, 2019.

BUTLER, Judith. Problemas de gênero: feminismo e subversão da identidade. Trad. Renato Aguiar. 15. ed. Rio de Janeiro: Civilização Brasileira, 2017.

CANCIAN, Natália; SALDAÑA, Paulo. Bolsonaro pede a MEC projeto de lei para proibir "ideologia de gênero". Folha de S.Paulo, São Paulo, 03 de setembro de 2019. Disponível em: https://www1. folha.uol.com.br/cotidiano/2019/09/bolsonaropede-a-mec-projeto-de-lei-para-proibir-ideologiade-genero.shtml. Acesso em: 22 jan. 2020.

CARVALHO, Marcos Castro; SÍVORI, Horacio Federico. Ensino religioso, gênero e sexualidade na política educacional brasileira. Cadernos Pagu [online], n. 50, 2017. Disponível em: https:// www.scielo.br/pdf/cpa/n50/1809-4449cpa-18094449201700500017.pdf. Acesso em: 10 jan. 2020.

CASE, Mary Anne. The role of the popes in the invention of complementarity and the Vatican's anathematization of gender. Religion \& Gender, v. 6, n. 2, p. 155-172, 2016.

CORRÊA, Sonia; KALIL, Isabela. Políticas antigénero en América Latina: Brasil ¿La catástrofe perfecta? Rio de Janeiro: Observatorio de Sexualidad y Política (SPW), 2020. Disponível em: https:// sxpolitics.org/GPAL/uploads/Ebook-Brasil\%20 20200204.pdf. Acesso em: 02 fev. 2020.

CRÍTICO da "doutrinação", Dória distribuirá livros de Mises a escolas. Carta Capital, 06 de abril de 2017. Disponível em: https://www.cartacapital. com.br/sociedade/critico-da-doutrinacao-doriaquer-livros-de-livre-mercado-nas-escolas/. Acesso em: 03 jan. 2020.

DARDOT, Pierre; LAVAL, Christian. A nova razão do mundo: ensaio sobre a sociedade neoliberal. Tradução Mariana Echalar. São Paulo: Boitempo, 2016.

FÉLIX, Anikó. Hungary. In: KOVÁTS, Eszter, PÕIM, Maari (ed.). Gender as a symbolic glue: the position and role of conservative and far right parties in the anti-gender mobilizations in Europe. 
Foundation for European Progressive Studies, 2015. p. 62-82.

FERREIRA, Lola; LEÃO, Natália. Central no discurso de posse, combate à "ideologia de gênero" é carta marcada há pelo menos oito anos por Bolsonaro. Gênero e Número, 02 de janeiro de 2019. Disponível em: http://www.generonumero. media/central-no-discurso-de-posse-combatea-ideologia-de-genero-e-carta-marcada-ha-pelomenos-oito-anos-por-bolsonaro/. Acesso em: 02 jan. 2020.

FOUCAULT, Michel. 0 nascimento da biopolítica: curso dado no Collège de France (1978-1979). Trad. Eduardo Brandão. São Paulo: Martins Fontes, 2008.

FOUCAULT, Michel. Vigiar e punir: o nascimento da prisão. Petrópolis, RJ: Vozes, 2014.

GRZEBALSKA, Weronica. Poland. In: KOVÁTS, Eszter; PÕIM, Maari (ed.). Gender as a symbolic glue: the position and role of conservative and far right parties in the anti-gender mobilizations in Europe. Foundation for European Progressive Studies, 2015. p. 83-103.

JUNQUEIRA, Rogério D. "Ideologia de gênero": uma categoria de mobilização política. In: SILVA, Márcia A. (org.). Gênero e diversidade: debatendo identidades. São Paulo: Perse, 2016. p. 229-246.

JUNQUEIRA, Rogério D. A invenção da "ideologia de gênero": a emergência de um cenário políticodiscursivo e a elaboração de uma retórica reacionária antigênero. Revista Psicologia Política, v. 18, n. 43, p. 449-502, set./dez. 2018.

KUHAR, Roman; ZOBEC, Aleš. The anti-gender movement in Europe and the educational process in public schools. C-E-P-S Journal, Ycar, v. 7, n. 2, p. 29-46, 2017.

LACLAU, Ernesto. A razão populista. São Paulo: Três Estrelas, 2013.

LOURO, Guacira Lopes L. Gênero, sexualidade e educação - uma perspectiva pós-estruturalista. Petrópolis, RJ: Vozes, 1997.

MACEDO, Elizabeth. Base Nacional Curricular Comum: novas formas de sociabilidade produzindo sentidos para educação. Revista e-Curriculum, São Paulo, v. 12, n. 3, p. 1530-1555, 2014.

"MAMADEIRAS eróticas" não foram distribuídas em creches pelo PT. Estadão, São Paulo, 28 de setembro de 2018. Disponível em: https:// politica.estadao.com.br/blogs/estadao-verifica/ mamadeiras-eroticas-nao-foram-distribuidas-em- creches-pelo-pt/. Acesso em: 23 jan. 2020.

MAYER, Stefani; SAUER, Birgit. "Gender ideology" in Austria: coalitions around an empty signifier. In: KUHAR, Roman; PATERNOTTE, David (org.). Anti-gender campaigns in Europe - mobilizing against equality. London: Rowman \& Littlefield Internacional Ltd., 2017. p. 23-40.

MIGUEL, Luis Felipe. Da "doutrinação marxista" à "ideologia de gênero" - Escola sem Partido e as leis da mordaça no Parlamento brasileiro. Revista Direito \& Práxis, Rio de Janeiro, v. 07, n. 15, p. 590-621, 2016.

MORENO, Meire Ellen. Feminismos e antifeminismos na política brasileira: "ideologia de gênero" no Plano Nacional de Educação 2014. 2016, 144 f. Dissertação (Mestrado em Ciências Sociais) Centro de Letras e Ciências Humanas, Universidade Estadual de Londrina (UEL), Londrina, PR, 2016.

MOSS, Kevin. Russia as the savior of European civilization: gender and the geopolitics of traditional values. In: KUHAR, Roman; PATERNOTTE, David (org.). Anti-gender campaigns in Europe mobilizing against Equality. London: Rowman \& Littlefield Internacional Ltd., 2017. p. 195-214.

MUELLE, Camila E. Cómo hacer necropolíticas en casa: ideología de género y acuerdos de paz en Colombia. Revista Latinoamericana Sexualidad, Salud y Sociedad, n. 27, p. 172-198, dec. 2017.

ORGANIZAÇÃO DAS NAÇÕES UNIDAS (ONU). ONU Mulher. Conferências mundiais da mulher. Disponível em: http://www.onumulheres.org.br/ planeta5050-2030/conferencias/. Acesso em: 02 jan. de 2020.

PAINS, Clarissa. "Menino veste azul e menina veste rosa", diz Damares Alves em vídeo. 0 Globo, Rio de Janeiro, 03 de janeiro de 2019. Disponível em: https://oglobo.globo.com/sociedade/meninoveste-azul-menina-veste-rosa-diz-damares-alvesem-video-23343024. Acesso em: 22 jan. 2020.

PENNA, Fernando. Escola sem Partido como chave de leitura do fenômeno educacional. In: FRIOGOTTO, Gaudêncio (org.). Escola "sem" partido: esfinge que ameaça a educação e a sociedade brasileira. Rio de Janeiro: UERJ, 2017. p. 35-49.

PENNA, Fernando; SALLES, Diogo da Costa. A dupla certidão de nascimento do Escola sem Partido: analisando as referências intelectuais de uma retórica reacionária. In: MUNIZ, Altemar de Costa; LEAL, Tito Barros (org.). Arquivos, documentos e ensino de história: desafios contemporâneos. 
Fortaleza: EdUECE, 2017. p. 13-37. Disponível em: https://professorescontraoescolasempartido.files. wordpress.com/2018/07/penna-e-salles-a-duplacertidc3a3o-de-nascimento-2017.pdf. Acesso em: 12 jan. 2020.

PERONI, Vera M. V.; CAETANO, Maria R.; ARRELARO, Lisete R. G. BNCC: disputa pela qualidade ou submissão da educação? RBPAE, v. 35, n. 1, p. 3556, jan./abr. 2019.

PETÕ, Andrea. Epilogue: "anti-gender" mobilisation discourse of conservative and far right parties as a challenge for progressive politics. In: KOVÁTS, Eszter; PÕIM, Maari (ed.). Gender as a symbolic glue - the position and role of conservative and far right parties in the anti-gender mobilizations in Europe. Foundation for European Progressive Studies, 2015. p. 126-131.

SCOTT, Joan. Gênero: uma categoria útil de análise histórica. Educação \& Realidade, v. 20, n. 2, p. 7199, jul./dez. 1995.

SILVA, Roberto R. D. da; SILVA, Denilson da; VASQUES, Rosane F. Políticas curriculares e financeirização da vida: elementos para uma agenda investigativa. Revista de Estudos Curriculares, v. 9, n. 1, p. 5-23, 2018.

SMITH, Bonnie G. Gênero e História: homens, mulheres e prática de histórica. Trad. Flávia Beatriz Rossler. Bauru, SP: EDUSC, 2003.

URIBE, Gustavo. Governo deve suspender edital com filmes LGBT criticados por Bolsonaro. Folha de S.Paulo, São Paulo, 19 de agosto de 2019. Disponível em: https://www1.folha.uol.com.br/ ilustrada/2019/08/governo-deve-suspenderedital-com-filmes-lgbt-criticados-por-bolsonaro. shtml. Acesso em: 02 jan. 2020.

VEIGA-NETO, Alfredo. Gubernamentalidad neoliberal: implicaciones para la educación. Revista Educación y Pedagogía, v. 22, n. 58, p. 213235, sep./dic. 2010.

WEEKS, Jeffrey. 0 corpo e a sexualidade. In: LOURO, Guacira L. (org.). 0 corpo educado. 3. ed. Trad. Tomaz Tadeu da Silva. Belo Horizonte: Autêntica, 2010. p. 35-82.

Recebido em: 05/03/2020

Aprovado em: 08/06/2020 